\title{
Harkaleh Watershed Ecological Capability Assessment for Agricultural Land with an Emphasis on the Sustainable Development
}

\author{
Katayoon Varshosaz ${ }^{1}$, Elham Mubarak Hassan ${ }^{2}$
}

\begin{abstract}
:
According to this study, ecological capability evaluation of land to develop agricultural and range management land uses were done based on spatial multi criteria evaluation and ovelay methods in Harkale in Lali city, southwestern Iran,2014. Ecological capability evaluation of land is one of the basic problems in environmental science. Following determination of the basin boundary on watershed topographic map (1:25000) and, analog maps were digitized in GIS environment. Next, data analysis were valued based on data collection analytical hierarchy process (AHP) method that it is one of the most typical of MCDM methods. Using AHP method, hierarchy structure of criteria was given in three level including objective, main criteria and sub criteria and weight matrixes were completed based on expert's opinion. Then, the matrixes were analyzed in Expert choice software to give of weight criteria. In next stage, weighting results of criteria were generalized to respective layers in GIS environment. Finally, 16data layers of ecological resources were overlaid and the final map of ecological capability of the study area was given and classified in six classes including very suitable, suitable, moderately suitable, less suitable, much less suitable and non developed parts. Also, using Makhdoum method, environmental units map was produced according to evaluation levels and overlaying of ecological data layers. Then, the final map of ecological capability of Harkale watershed for developing agriculture and range management land uses was given based on SQL method. The results showed that in AHP method, suitable development of agriculture and range management land uses are allocate 1005 and 1242 ha of the study area (3855 ha) while in Makhdoum method these area contained 713 and 1568 ha, respectively. Totally, Harkale watershed has moderate ecological capability for developing agriculture and range management land uses.
\end{abstract}

Keywords: Ecological capability evaluation, Multi criteria evaluation, Analytical hierachy Process ( AHP) ,Makhdoom model,GIS

\section{Introduction}

Ecological capability evaluation is a process which attempts to provide an appropriate development and consistent with nature, by regulating the relationship between human and the nature. In fact, this evaluation is an effective step towards obtaining a program for sustainable development, because with identifying and evaluating ecological characteristics in each region, development programs can be organized along with the nature and nature itself identifies potentials for development. Considering the conditions of our country's biological resources, it is necessary to conduct any plan on establishment of various industrial, agricultural or forestry activities, by considering the capacity of the land and within the context of environmental

2 Department of Environment, Ahvaz Branch, Islamic Azad University, Ahvaz, Iran. 
potentials and capacities and by considering spatial planning thought and principles of sustainable development. One of the key issues in the process of spatial planning is ecological capability evaluation of a land. Ecological capability evaluation leads to allocation of lands based on their natural potentials to their proper applications (farming, pasture management, industrial urbanization and etc.) and this issue, while protects the natural resources and produces income at the national level, will not reduce or alter the quality of land and as a result, by establishment of ecological balance, comprehensive development of national and regional environment will be ensured.

\section{Study area}

Harkaleh Basin, with an area of 3850 hectares is located in the northeast of Khuzestan province, in the region of Zagros. Also, its villages include Sar Kooli Olia, Sar Kooli Sofla, Mahmoud Abad, Hayatabad and Manari Abad. The majority of its people are involved in animal husbandry and agricultural jobs. The study area due to its climatic characteristics and pastures has appropriate conditions for animal husbandry. In the past, Harkaleh plain was the winter quarters for nomads and over time most of them decided to settle and only few of them took their animals to summer pastures in Chaharmahal va Bakhtiari province. In the process of nomadism, agriculture (farming and horticulture) has a special importance along with animal husbandry, as an auxiliary and complementary activity. The study area has not developed in terms of agriculture, due to some reasons including lack of sufficient water, its special topography, having rocky lands and inadequate familiarity of its people with agricultural techniques and we can say that the economy of this region mostly relies on animal husbandry. However farmers plant rain-fed wheat and barley in this area with traditional methods.

The study area, in terms of topography consists of mountainous areas, hills and plains and its current use includes forest lands, pastures and rain-fed farming. However, due to the existence of sufficient water resources in the region and its proximity to the river, it seems that it has the potential for irrigated agriculture as well.

\section{Identification of environmental resources}

\section{Climate}

\section{Precipitation}

In order to determine the average annual precipitation in the area of Harkaleh, after completion of annual precipitation data of studied stations, for a long-term and common statistical period, we studied and evaluated the correlation between annual precipitation and their seating altitudes. The average annual precipitation in this basin was estimated to be $551 / 2 \mathrm{~mm}$ and its average altitude was 480 meters above the sea level.

\section{Temperature}

In order to assess the monthly and annual changes in temperature, in the area of Harkaleh, statistics and information of Lali evaporation station have been used. The 
average annual temperature in this area is $24 / 7^{\circ} \mathrm{C}$, the absolute minimum temperature is $-1 / 5^{\circ} \mathrm{C}$ in January and the absolute maximum temperature is $50^{\circ} \mathrm{C}$ in July.

\section{Topography}

In terms of topography, the study area consists of mountainous areas, hills and plains and despite its small area; it has a good ecological diversity.

\section{Geology}

In terms of geological structure, Harkaleh basin is considered as a part of Folded Zagros. Folded Zagros or external Zagros is located in southwest of Iran and its width is estimated to be about 200 to 300 kilometers and in some areas it has been probably drawn under the Zagros Thrust.

\section{Soils}

Soils in the study area are divided into two groups, in terms of the impact of time factor in their formation and evolution. The first group includes those soils which have not been enough evolved due to the lack of suitable soil-forming conditions and due to erosion and sedimentation and they have not made specific horizons. This group is classified in the category of Entisols. The second group includes those soils which over time have evolved to some extent as a result of their transformation.

\section{Vegetation}

About 1,200 hectares of the study area consist of forest and forest lands, 1,600 hectares consist of pastures and 1060 hectares consist of rain-fed farming.

\section{Method}

- Identification of ecological resources

- Determination of criteria and sub-criteria and formation of hierarchical structure, by using specialized software of Expert Choice and conducting paired comparisons

Determination of relative weights and coefficients of digital layers of scale base maps, based on the Analytic Hierarchy Process and by using specialized software of Expert Choice

- According to the results, before taking action and in the GIS software, the weights of each criterion will be generalized to the related maps (generating standard maps)

- Standardization (reclassification) of maps obtained from previous step

- Multiplying standard map layers in respective weights and preparing standardized weighted maps

- Overlaying and combining maps and obtaining ecological capability maps for agriculture and pasture management

At the first level of the hierarchy, the target (capability evaluation for agricultural use) is given.

At the second level, we have specified criteria or indicators, by which we intend to achieve the target which include 16 natural parameters of precipitation, temperature, slope, slope direction, elevation levels, soil depth, soil texture, soil structure, soil 
permeability and soil erosion, plant species, vegetation density, geological formation, sensitivity to erosion, discharge of basins and water resources.

Note that, forage production capacity will be added to the criteria in order to evaluate the land use for pasture management.

By considering appropriateness of the lands of the study area for agriculture and pasture management uses in the third level of the hierarchical analysis, we divided the lands in terms of appropriateness into six groups or categories of very good place, good place, inappropriate place, very inappropriate place and finally undevelopable place.

Parameters of altitude, slope, direction, plant species and etc. were studied in order to make map layers.

Standard maps were reclassified and reweighted in 6 classes, in order to determine the land use, based on the AHP method. After completing database of map layers, based on what was mentioned in the table, now with applying pixel size of $10 \mathrm{~m}$, we should convert all the maps from vector format to raster format, with the help of AHP_CODE field; because in capability evaluation, overlaying and comparison of maps is only possible in a coordinated and homogenous raster format and with equal cell sizes.

\section{- The second method: Makhdoom systematic analysis method}

In this method, the process of ecological capability evaluation is summarized as follows:

\section{(A) Identification of ecological resources:}

Resources which are required for ecological capability evaluation include physical and biological resources which constitute sustainable and unsustainable ecological resources. This information includes topographic conditions, weather and climate, geology, soil, hydrology and vegetation. It should be noted that since the discussion of "identification of ecological resources" is the common base of both of methods, it has been explained at the beginning of this chapter.

\section{(B) Analyzing and summarizing the resources}

To conduct ecological capability evaluation, information on ecological resources in this basin should be integrated; so, information layers will be integrated, according to Mac Hark (1969) method and therefore a map that represents the characteristics of all layers, can be obtained as follows:

The first step - Integrating elevation levels map with slope degree and slope direction maps (creating topographic map)

The second step - Integrating topographic map with the soil type map (creating the first environmental units map)

The third step - Integrating the first environmental units map with vegetation type map (creating the second environmental units map)

The fourth step - Integrating the second environmental units map with vegetation density map (creating sustainable environmental units map)

The fifth step - Integrating sustainable environmental units map with unsustainable resources map (creating the final map of environmental units)

The sixth step- completing environmental units table by using information on geology, climate and.... 


\section{(C) Evaluation of environmental capability for agriculture and pasture management}

\section{Results}

In this study we evaluated ecological capability and natural potentials of Harkaleh basin -located in the city of Lali- for agricultural and pasture management land uses, by using Analytical Hierarchy Process or AHP method, which is an important and widely used technique in Spatial Multi Criteria Evaluation (SMCEM) and also by using another approach, called "Makhdoom systematic analysis method" and by utilizing GIS software as well.

Analytical Hierarchy Process (AHP) is based on setting targets, forming hierarchical structure, conducting paired comparisons for criteria based on expert opinions, weighting the criteria and then overlaying the layers of standard maps in the GIS software and generating ecological capability maps of study area. The results which have been obtained through applying this method indicate that from total area of 3855 hectares, 1005 hectares of the land are appropriate for agriculture and 1242 hectares are suitable for pasture management in different degrees. Makhdoom systematic analysis method is based on three steps of identification of resources, analysis and integration of resources and eventually evaluation of ecological capability and it is based on creating environmental units map and comparing each of the units with ecological model. The results of this method indicate that in this basin, 713 hectares of the land are appropriate for agriculture and 1568 hectares are suitable for pasture management.

Table1. Summary of ecological capability evaluation of Harkaleh basin in the city of Lali

\begin{tabular}{|l|l|l|l|}
\hline $\begin{array}{l}\text { Capability } \\
\text { classes }\end{array}$ & $\begin{array}{l}\text { Makhdoom method } \begin{array}{l}\text { For agriculture and pasture } \\
\text { management land uses } \\
\text { Area (ha) }\end{array} \\
\begin{array}{l}\text { AHethod } \\
\text { For } \\
\text { agriculture } \\
\text { Area (ha) }\end{array}\end{array}$ & $\begin{array}{l}\text { AHP method } \\
\text { For pasture } \\
\text { management } \\
\text { Area (ha) }\end{array}$ \\
\hline 1 & - & 401 & 112 \\
\hline 3 & 256 (agriculture) & 501 & 847 \\
\hline 4 & 475 (agriculture) & 103 & 283 \\
\hline 5 & 124 (pasture management) & 177 & 114 \\
\hline 6 & 271 (pasture management) & 850 & 1155 \\
\hline 7 & 1173 (pasture management) & 1823 & 1344 \\
\hline Total & 1574 & - & - \\
\hline
\end{tabular}

In terms of size and area, this basin is not ecologically capable for agricultural and pasture management land uses. The area obtained from both methods is almost equivalent; in other words, both of research methods were equally potent in terms of identification of inappropriate lands for agricultural and pasture management land uses. 


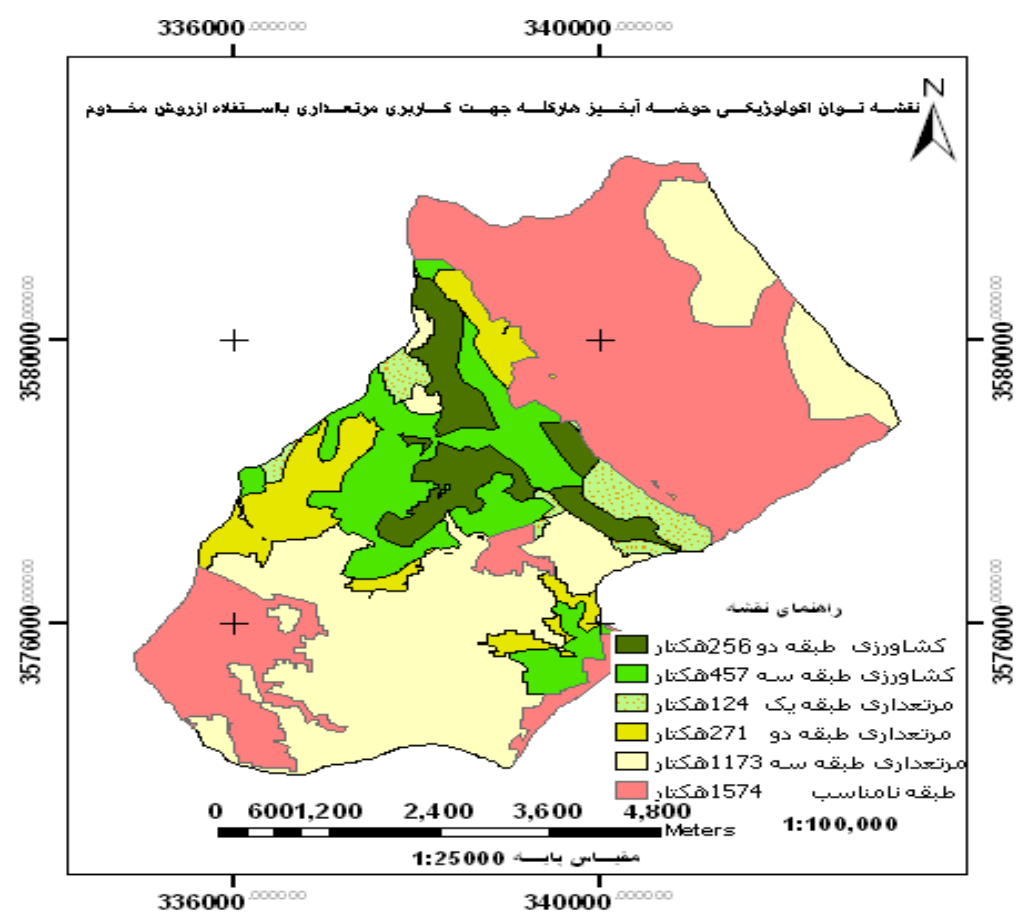

Map No.1. The final map of ecological capability evaluation of Harkaleh basin, for agricultural and pasture management land uses, through using Makhdoom method

Also, summarizing the obtained information indicates that about 60 percent of the lands are appropriate for agriculture and pasture management land uses and the rest, that is approximately $40 \%$ lacks the required conditions for agriculture and pasture management and that part is mostly suitable for conservation purposes and forestry and that is due to some reasons including its small area, its particular topographical conditions (roughness and high slopes), geological formation, shallow soil and existence of woodlands.

In addition, reviewing charts obtained from software of Expert Choice shows that in agricultural land use, the highest weights belong to criteria of climate, soil, topography, hydrology, vegetation and geology, respectively. Also, regarding pasture management, the highest weights belong to criteria of vegetation, climate, soil, topography, hydrology and geology, respectively.

Also in agricultural land use, precipitation, slope and soil texture, respectively possess the highest weights among ecological sub criteria and in pasture management land use, precipitation, vegetation density and vegetation type possess the highest weights respectively.

Comparing the results of two research methods

Comparing the results of two research methods suggests that in the Analytic Hierarchy Process the amount of suitable lands with ecological capability for agriculture is more, in comparison with Makhdoom systematic analysis method. Also, the amount of suitable 
land for pasture management in the AHP method is more and it is probably because of following reasons:

Firstly in the AHP method, ecological criteria and sub criteria have been weighted based on the opinions and views of local experts and these opinions have been considered in illustration of final ecological capability evaluation map of study area; so it illustrates a clearer and more realistic picture of capabilities of the land; while Makhdoom method is being conducted systematically and based on pre-assumptions and on the basis of a predesigned model and it doesn't regard the opinions of local experts.

Secondly, the model presented by doctor Makhdoom is a general model which has been designed by considering ecological conditions of Iran and it is mostly applicable at the regional and national levels; while AHP method studies details of local ecological parameters of the basin and with respect to its accuracy and transparency in decisionmaking, this method can better manifest capabilities of the land in small basins.

Thirdly, as discussed earlier, in Makhdum method, because of unclear boundary between rain-fed agriculture and pasture management, agricultural and pasture management land uses are evaluated under one model; while in AHP method these land uses are evaluated separately.

Also, comparison of research results with current land use map of the area shows that currently the amount of farming in this area exceeds its ecological capability and by considering those parts of the forest and pasture lands which unsystematically have been converted to dry lands, we can say that its ecological capability for agriculture has not been observed and field visits also confirm this fact.

Harkaleh basin, located in the city of Lali, has a mediocre potential for agricultural and pasture management land uses and by imposing proper management and avoiding unprincipled exploitation of the lands, maximize ecological capability and natural potential of the area may be achieved. 
